\title{
Perancangan Sistem Informasi Peminjaman Alat dan Peralatan Laboratorium Berbasis RFID
}

\section{The Design of Laboratory Equipments Lending Information System based on RFID}

\author{
Akhmad Choerudin ${ }^{1, *}$, Jaka Windarta ${ }^{2}$, Sumardi $^{3}$ \\ ${ }^{\#}$ Program Studi Pendidikan Profesi Insinyur, Fakultas Teknik, Universitas Diponegoro \\ Jl. Prof. Soedarto, SH., Tembalang, Semarang, Jawa Tengah, Indonesia \\ 1,*Penulis korespondensi: akhmadchoerudin@students.undip.ac.id \\ 2jakawindarta@lecturer.undip.ac.id, ${ }^{3}$ sumardi@elektro.undip.ac.id
}

Received on 21-05-2021, accepted on 08-07-2021, published on 17-07-2021

\begin{abstract}
Abstrak
Laboratorium membutuhkan sebuah perancangan sistem informasi otomatis untuk mempermudah dalam proses pinjam meminjam barang. Perancangan sistem peminjaman alat dan barang berbasis RFID di Laboratorium Teknik Elektro IT Telkom Purwokerto diharapkan dapat membantu mempermudah manajemen peminjaman alat dan barang dan memoderenisasi sistem yang ada pada saat ini. Alat ini bekerja dengan cara membaca Frequency RFID Tag yang terdapat dikartu identitas peminjam menggunakan sensor RFID reader, kemudian menampilkan pesan pada layar Liquid Cristal Display (LCD) berupa kode RFID Tag tersebut. RFID reader ini dapat membaca dengan jarak efektif kurang dari $5 \mathrm{~cm}$ dengan sudut kemirringan pembacaan ideal 0․ Percobaan pembacaan RFID Tag dilakukan dengan total 15 Kartu RFID, dengan skenario pengujian pembacaan sensor RFID reader terhadap jarak dari $1 \mathrm{~cm}$ sampai dengan $3 \mathrm{~cm}$ mendapatkan hasil pembacaan baik, pada jarak $4 \mathrm{~cm}$ terdapat 4 kartu yang dapat dibaca dan 11 kartu yang gagal, dan pada jarak $5 \mathrm{~cm}-7 \mathrm{~cm}$ kartu RFID semuanya gagal terbaca. Pembacaan kartu RFID berdasarkan sudut kemiringan 15 sampai dengan 90 mendapatkan hasil 15 - 80 kartu dapat terbaca dengan baik, sedangkan pada sudut 90 으 semua kartu gagal dibaca. Serta pengambilan data QOS (Quality of Service) dengan variasi waktu yang berbeda beda yaitu 1 menit, 3 menit, 5 menit, 7 menit, 10 menit, 13 menit dan 15 menit didapatkan rata rata Delay 2,49 detik, throughtput 958,14 bps, dan Packet Loss -0,0014\%.
\end{abstract}

Keywords: Delay, Paket Loss, Quality of Service, RFID, Throughtput.

Abstract

The laboratory needs an automatic information system design to facilitate the process of borrowing and lending equipment. The design of an RFID-based lending system at the Electrical Engineering Laboratory, IT Telkom Purwokerto, is expected to modernize the current system by improving the store and lending system. This RFIDbased tool works by reading the Frequency RFID Tag contained on the borrower's identity card using an RFID reader sensor, then displaying a message on the Liquid Crystal Display (LCD) screen in the form of the RFID Tag code. This RFID reader can read with an effective distance of less than $5 \mathrm{~cm}$ with an ideal reading angle of 0. The RFID Tag reading experiment was carried out with 15 RFID cards. The distance test scenario was placing an RFID card above the reader sensor. At a distance from 1 to $3 \mathrm{~cm}$, the tag is well-read. At a distance of $4 \mathrm{~cm}, 4$ cards can be read, and the other 11 are failed. At a $5-7 \mathrm{~cm}$ distance, all RFID cards were failed to be read. The angle test was carried out by tilting the angle of the card from 150 to 90\%. Results in 150 - 80 - tilt angle, call ards can be read correctly. While at an angle of 90 ㅇ, all cards are failed to be read. The data was taken for the Quality of Service test by different time variations: $1,3,5,7,10,13$, and 15 minutes. The results are: an average delay is 2.49 seconds, throughput is 958.14 bps, and Packet Loss $-0.0014 \%$.

Keywords: Delay, Paket Loss, Quality of Service, RFID, Throughtput. 


\section{PENDAHULUAN}

Di zaman modern ini sangat mudah untuk mencari segala jenis informasi bahkan dari seluruh penjuru dunia. Salah satu tempat untuk mencari informasi lebih detail tentang suatu pengujian atau percobaan adalah dilaboratorium. Dalam dunia pendidikan, laboratorium memiliki peranan penting untuk menunjang proses pembelajaran Mahasiswa atau Siswa baik dalam proses pengambilan data, praktikum dan tempat pendukung penelitian.

\section{KAJIAN PUSTAKA}

Penelitian oleh Dani Yusuf dengan judul Sistem Peminjaman Barang di Perusahaan Menggunakan Teknologi RFID. Penelitian ini bertujuan untuk memudahkan pegawai dalam melakukan pegawasan, pendataan yang revelan, sehingga cost yang berlebihan dapat dihindari memudahakan pengolahan data peminjaman asset dengan kartu RFID. Peneltian Dani Yusuf ini menggunakan metode Waterfall yaitu Requirement, Design, Implementation, Verification \& Validation, dan Operation \& Maintenance[1]. Penelitian oleh Ashar Ruslan dengan judul Sistem Peminjaman Dan Keamanan Pada Perpustakaan Menggunakan RFID. Tujuan dari penelitian dari Ashar Ruslan ini adalah untuk merancang sebuah sistem keamanan untuk memelihara dan menjaga koleksi koleksi buku - buku diperpustakaan. Penelitian in menggunakan Arduino Uno sebagai mikrokontoller, dan mendapatkan masukan dari RFID sebagai masukan utama untuk mendeteksi buku buku dalam melakukan suatu peminjaman dan proses keamanan suatu buku[2].

\section{A. Definisi Radio Frequency Identification (RFID)}

Radio Frequency Identification ( RFID ) sering kita jumpai diperkantoran, transportasi public, dan tempat perkuliahan dimana mahasiswa atau karyawan menggunakan kartu RFID untuk identitas mereka. Ukuran dan bentuk RFID sebagai identitas ini bermacam - macam ada yang berupa kartu, sticker, dan gantungan kunci. Walaupun terdiri dari bermacam macam, fungsi RFID sebagai identitas adalah tetap sama yaitu menyimpan kode sebagai identitas seseorang atau barang tertentu. Radio Frequency Identification ( RFID ) yang digunakan di Kawasan IT Telkom Purwokerto adalah berupa RFID Tag, RFID Tag ini berbentuk seperti kartu dengan ukuran $(8.5 \mathrm{~cm} \times 5.5 \mathrm{~cm})[3]$.

\section{B. Sensor RFID reader Mifare - RC522}

Mifare RC-522 merupakan modul RFID interrogator yang bekerja pada frekuensi $13.56 \mathrm{MHz}$. Sensor RC422 ini mendukung mode ISO 1443A/MIFARE. Modul ini menggunakan SPI untuk berkomunikasi dengan mikrokontroller.

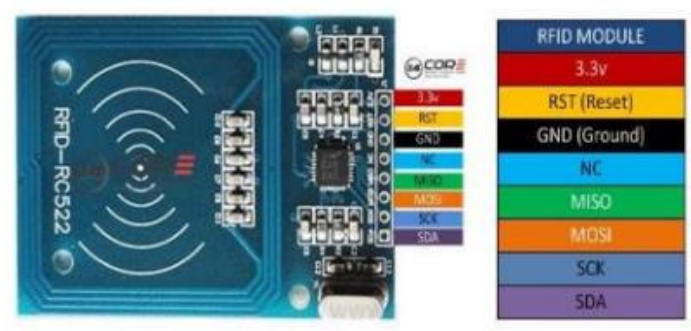

Gambar 1. Sensor Mifare RC-522 [4]

\section{NodeMCU ESP8266}

NodeMCU adalah sebuah platform Internet of Things(IoT) yang bersifat open source. Terdiri dari perangkat keras yang berupa System On Chips ESP8266 dari ESP8266 buatan Espressif System, juga firmware yang digunakan, yang menggunakan Bahasa pemrograman Scripting Lua. Istilah NodeMCU 
secara default sebenarnya mengacu pada firmware yang digunakan daripada perangkat keras development kit. NodeMCU juga dapat dianalogikan sebagai board Arduino-nya ESP8266.

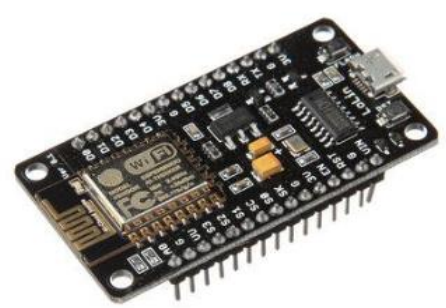

Gambar 2. Tampilan NodeMCU ESP8266 [5]

\section{PENGUJIAN QUALITY OF SERVICES JARINGAN}

Pada pengujian Quality of Services yang digunakan dalam penelitian ini adalah untuk mengukur kemampuan layanan jaringan Hardware yang terhubung ke server lokal. Dalam pengujian QOS ini dapat diketahui diantaranya adalah Delay, Packet Loss, dan Throughput.

\section{DELAY ( WAKTU TUNDA )}

Dengan memperhitungkan waktu Delay, maka dapat diketahui waktu yang dibutuhkan data untuk menempuh jarak dari asal sampai ke tujuan, dalam penelitian ini yaitu di mulai dari data masuk ke RFID reader sampai ke server lokal. Untuk data pengujian yang diambil pada penelitian ini adalah sejumlah 15 sample kartu RFID, masing masing pengujian dengan variasi waktu yang berbeda. Satuan dari Delay adalah second, dan bisa dikonversikan ke millisecond.

\section{THROUGHPUT}

Throughput untuk mengetahui jumlah total kedatangan paket sukses yang diamati pada tujuan selama interval waktu tertentu dibagi oleh durasi interval waktu tersebut. Satuan dalam Throughput adalah bps (bit persecond). Throughput juga memiliki definisi kecepatan (rate) transfer data efektif.

\section{PACKET LOSS ( PAKET HILANG )}

Untuk Packet Loss yang dihitung dalam penelitian kali ini adalah parameter yang digambarkan suatu kondisi yang menunjukan jumlah paket yang hilang. Dan satuan yang berlaku pada Packet Loss adalah persen $(\%)$

\section{METODOLOGI PENELITIAN}

\section{A. Alur Penelitian}

Alur penelitian untuk perancangan studi kasus ini bisa digambarkan pada Gambar dibawah ini : 


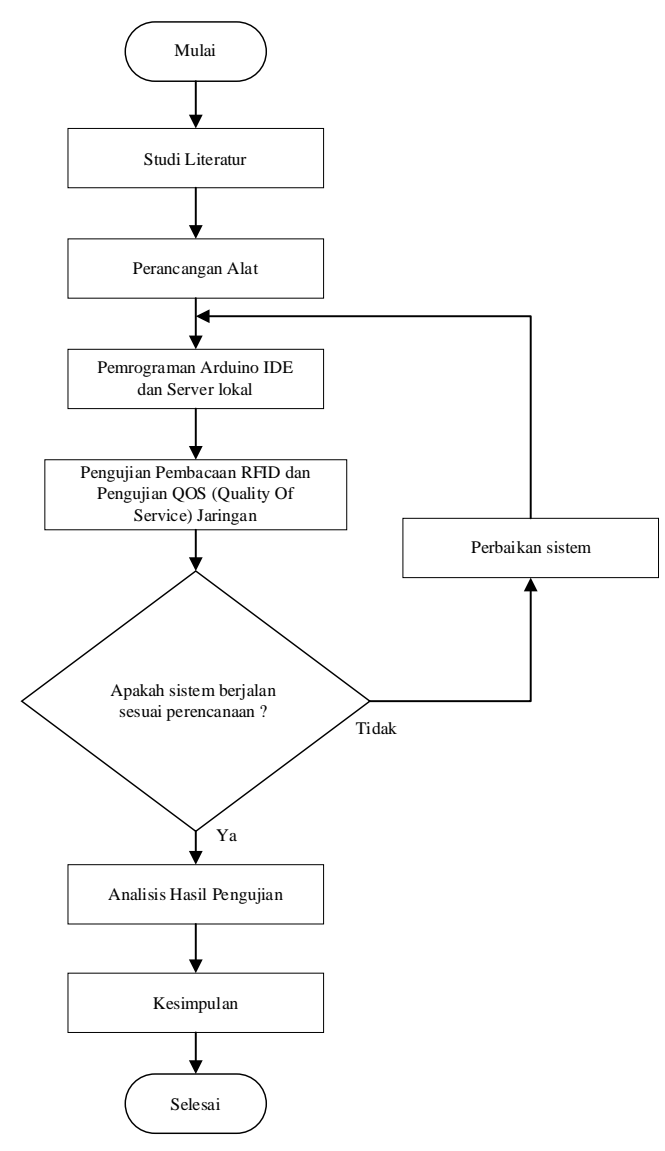

Gambar 3 . Diagram alur penelitian

Gambar 3 merupakan alur penelitian yang dilakukan dalam perancangan penelitian ini. Terlihat dari gambar 3 dimulai dari studi literatur adalah dengan serangkaian kegiatan untuk mengumpulkan data pustaka informasi yang diperlukan, dan referensi dari rekan rekan. Dan diakhiri dengan pengambilan kesimpulan. Pada gambar 3.1 flowchart alur penelitian juga terdapat proses perbaikan sistem. Perbaikan sistem diperlukan apabila selama percobaan berlangsung terdapat hasil pengujian yang tidak sesuai dengan perencanaan atau konsep yang sudah dibuat.

\section{B. Perancangan Sistem Alat}

Pada penelitian yang dibuat pada kesempatan ini, penulis membuat perancangan sistem informasi peminjaman alat dan barang berbasis RFID.

\section{Arsiteksur Dasar Hardware}

Pembuatan sistem Hardware pada penelitian ini, dibuat sebagai langkah awal perencanaan alat yang akan dirancang. Berikut Gambar 3.2 sebagai ilustrasi arsitektur dasar Hardware penelitian.

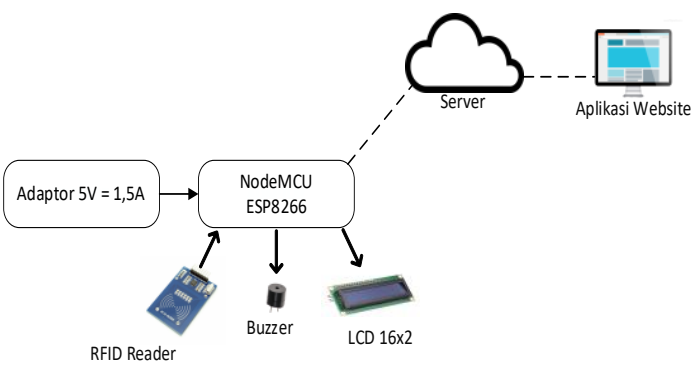

Gambar 4. Arsitektur Dasar Hardware 
Gambar 4 merupakan gambaran arsitektur dasar Hardware yang akan dirancang. Alat ini digunakan untuk membaca kartu identitas ( Kartu RFID ) yang dibawa oleh peminjam alat. Setelah RFID reader dapat membaca kode didalam kartu RFID selanjutnya akan memprosesnya didalam NodeMCU ES8266 dan selanjutnya akan ditampilkan informasi kode kartu tersebut pada LCD 16x2. Dan NodeMCU ESP8266 juga bertindak sebagai media untuk terhubung dengan server local. Selanjutnya pada penelitian ini menggunakan MySQL dan phpMyAdmin untuk proses menyimpan data identitas peminjam barang dan menyimpan data asset atau alat yang terdapat dilaboratorium, yang nantinya akan ditampilkan pada sebuah aplikasi website.

\section{Perancangan Ilustrasi Hardware Menggunakan Fritzing}

Perancangan Hardware yang dikerjakan pada penelitian ini menggunakan beberapa komponen dan alat. Perancangan alat ini terdiri dari sensor RFID reader RC522, Kartu RFID (13,56 MHz), NodeMCU 8266, Buzzer, Adaptor 5V-1,5A, dan LCD 16x2. Untuk ilustrasi perancangan Wiring Hardware dapat digambarkan seperti Gambar 5.

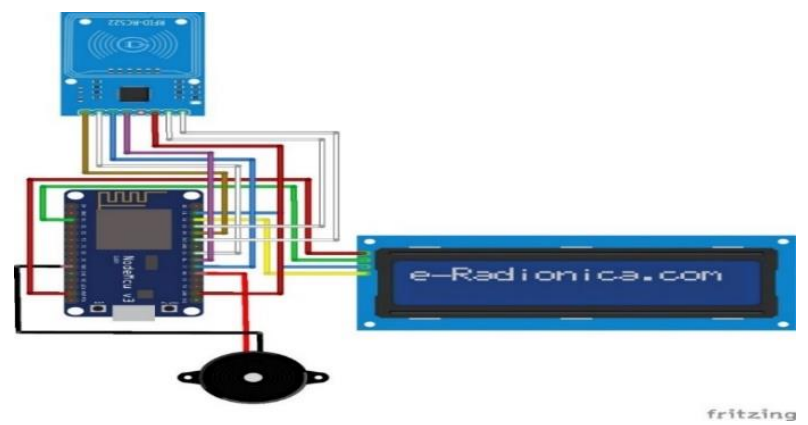

Gambar 5. Wiring diagram sistem perancangan Hardware menggunakan aplikasi fritzing.

Pada gambar 5 Wiring diagram terdapat NodeMCU sebagai pusat pemrosesan dan kendali dari input berupa RFID sensor dan keluaran Buzzer dan LCD yang dirancang. Pada tahap pertama NodeMCU diberikan tegangan sebesar 5 VDC-1,5A, sensor yang menjadi input adalah sensor RFID reader RC522, sedangkan outputnya adalah berupa suara dari Buzzer dan juga informasi dilayar LCD 16x2. Media komunikasi yang digunakan untuk mengubungkan perangkat keras dengan server lokal adalah dengan menggunakan Wifi, dimana didalam server lokal terdapat penyimpanan data, pengelolaan web, dan management akun. Dan menggunakan aplikasi website sebagai penampil interaksi informasi kepada pengguna aplikasi ini.

\section{Hasil dan Pembahasan}

Penelitian ini menganalisis dari pengujian QOS (Quality of Services) menggunakan protocol filter HTTP pada pengambilan data menggunakan software wireshark, dan menggunakan jaringan layanan Wifi dengan variasi waktu pembambilan data yang berbeda yaitu 1 menit, 3 menit, 5 menit, 7 menit, dan 10 menit, 13 menit, dan 15 menit. Pengujian ini diimplementasikan pada sistem perancangan alat yang sudah dibuat.

\section{Delay}

Pada pengujian Delay menggunakan software wireshark nilai rata rata Delay dapat dilihat pada kolom time delta from previous displayed frame yang terdapat pada fitur wireshark, dimana Delay pengiriman data dari NodeMCU menuju server local dan NodeMCU mendapatkan reply dari server local.

Tabel 1. Hasil Pengujian Rata-Rata Delay (Second)

\begin{tabular}{|c|c|c|c|c|c|c|c|c|}
\hline \multirow{2}{*}{ Parameter } & \multirow{2}{*}{ Skenario } & \multicolumn{7}{|c|}{ Waktu Pengukuran (menit) } \\
\cline { 3 - 9 } & & 1 & 3 & 5 & 7 & 10 & 13 & 15 \\
\hline Delay (Second) & Normal & 2,32 & 2,48 & 2,5 & 2,54 & 2,54 & 2,53 & 2,54 \\
\hline
\end{tabular}




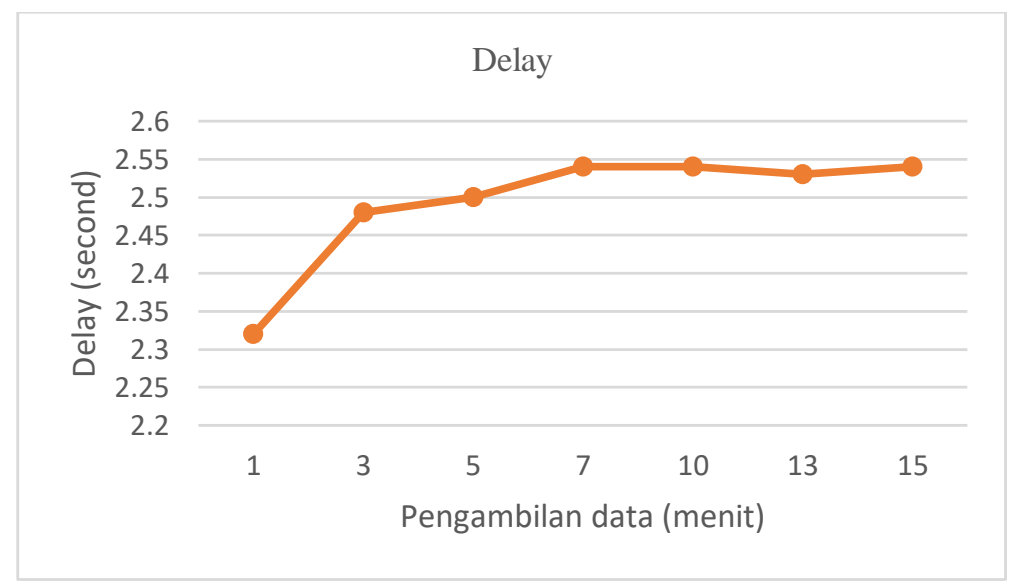

Gambar 6. Hasil Pengujian Delay Dengan Variabel Waktu

Dari hasil pengujian Delay yang dilakukan diatas, hasil pengujian Delay menunjukan pada pengambilan data pertama yaitu 1 menit mendapatkan rata-rata Delay 2,32 detik, pengambilan data kedua yaitu 3 menit mendapatkan rata-rata 2,48 detik, pengambilan data ketiga yaitu 5 menit mendapatkan rata-rata 2,5 detik, pengambilan data keempat yaitu 7 menit mendapatkan rata-rata 2,54 detik, pengambilan data kelima yaitu 10 menit mendapatkan rata-rata 2,54 detik, pengambilan data kenam yaitu 13 menit mendapatkan rata-rata 2,53 detik dan pengambilan data ketujuh yaitu 15 menit mendapatkan rata-rata 2,54 detik. Berdasarkan semua pengambilan data Delay dari rata-rata 2,32 detik sampai dengan 2,54 detik

\section{Analisis Throughput}

Tabel 2 Pengujian Throughput Dengan Variable Waktu

\begin{tabular}{|c|c|c|c|c|c|c|c|c|}
\hline \multirow{2}{*}{ Parameter } & \multirow{2}{*}{ Skenario } & \multicolumn{7}{|c|}{ Waktu Pengukuran ( Menit ) } \\
\cline { 3 - 9 } & 1 & 3 & 5 & 7 & 10 & 13 & 15 \\
\hline $\begin{array}{c}\text { Throughput (bit } \\
\text { persecond / bps) }\end{array}$ & Normal & 1029,43 & 963,56 & 953,02 & 937,23 & 940,53 & 942,06 & 941,21 \\
\hline
\end{tabular}

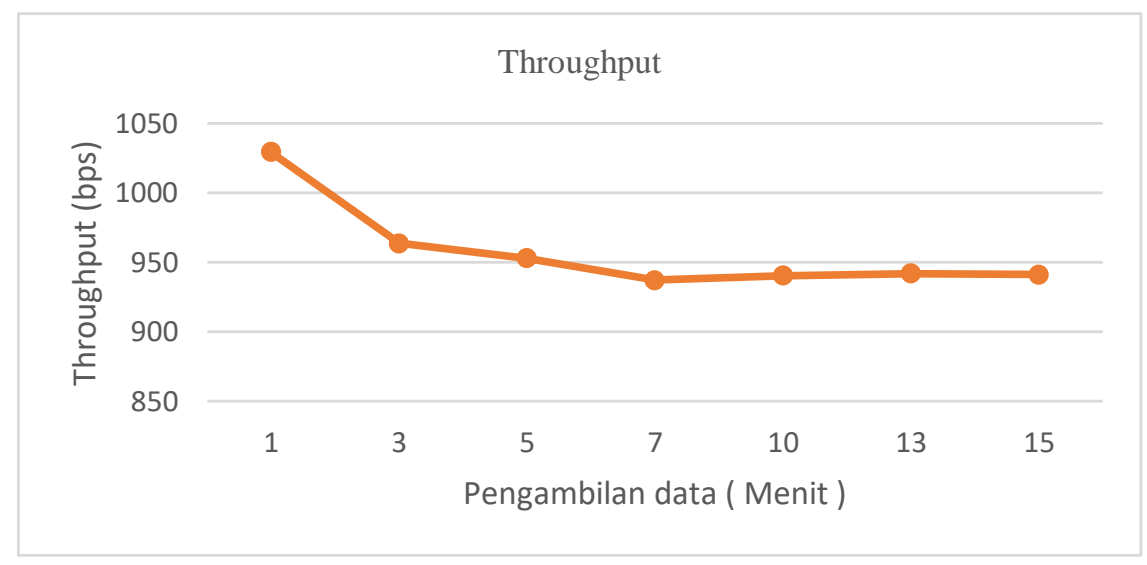

Gambar 7. Hasil Pengujian Throughput Dengan Variable Waktu

Dari hasil pengujian Throughput yang dilakukan diatas, hasil pengujian Throughput menunjukan pada pengambilan data pertama yaitu 1 menit mendapatkan rata-rata Throughput 1029,43 bps, pengambilan data kedua yaitu 3 menit mendapatkan rata-rata Throughput 963,56 bps, pengambilan data ketiga yaitu 5 menit mendapatkan rata-rata Throughput 953,02 bps, pengambilan data keempat yaitu 7 menit mendapatkan ratarata Throughput 937,23 bps, pengambilan data kelima yaitu 10 menit mendapatkan rata-rata Throughput 940,53 bps, pengambilan data keenam yaitu 13 menit mendapatkan rata-rata Throughput 942,06 bps, dan 
pengambilan data ketujuh yaitu 15 menit mendapatkan rata-rata Throughput 941,21 bps. Berdasarkan semua pengujian pengambilan data Throughput yang dilakukan mendapatkan hasil 937,23 bps sampai dengan 1029,43 bps, dapat dikategorikan hasil Throughput yang didapatkan berdasarkan standarisasi TIPHON adalah sangat bagus.

\section{Analisi Packet Loss}

Tabel 3 Pengujian hasil Delay dengan variable waktu

\begin{tabular}{|c|c|c|c|c|c|c|c|c|}
\hline \multirow{2}{*}{ Parameter } & \multirow{2}{*}{ Skenario } & \multicolumn{7}{|c|}{ Waktu Pengukuran (Menit ) } \\
\cline { 3 - 8 } & & 1 & 3 & 5 & 7 & 10 & 13 & 15 \\
\hline $\begin{array}{c}\text { Packet Loss } \\
\text { Persen / \% })\end{array}$ & Normal & 0 & 0 & 0 & -0.01 & 0 & 0 & 0 \\
\hline
\end{tabular}

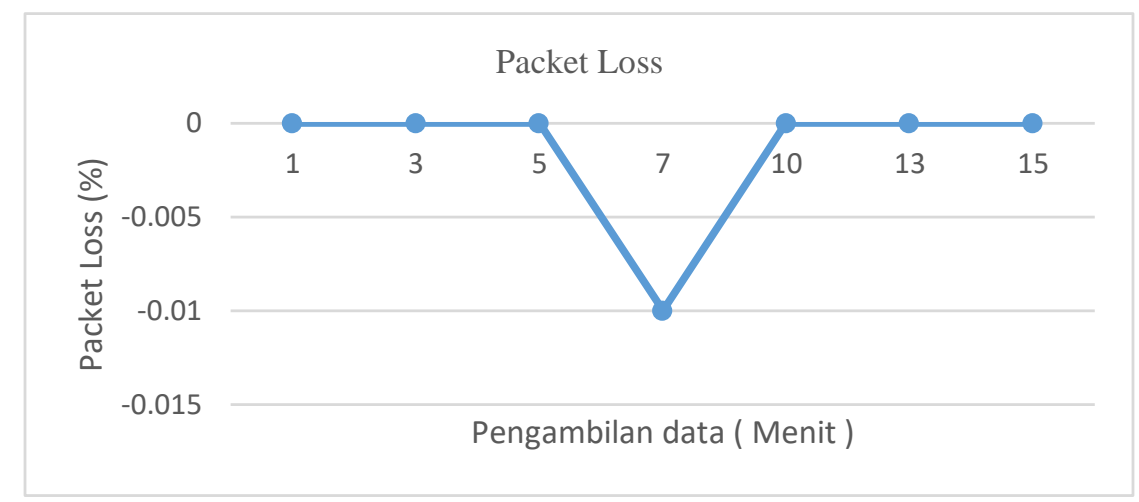

Gambar 8. Hasil Pengujian Packet Loss Dengan Variable Waktu Tertentu

Dari hasil pengujian Packet Loss yang dilakukan diatas, hasil pengujian Packet Loss menunjukan pada pengambilan data pertama yaitu 1 menit mendapatkan rata-rata Packet Loss $0 \%$, pengambilan data kedua yaitu 3 menit mendapatkan hasil $0 \%$, pengambilan data ketiga yaitu 5 menit mendapatkan hasil $0 \%$, pengambilan data keempat yaitu 7 menit mendapatkan hasil $-0,01 \%$, pengambilan data kelima yaitu 10 menit mendapatkan hasil $0 \%$, pengambilan data keenam yaitu 13 menit mendapatkan hasil $0 \%$, dan pengambilan data ketujuh yaitu 15 menit mendapatkan hasil $0 \%$. Berdasarkan semua hasil pengujian paket loss yang didapatkan yaitu dari -0,01\% sampai dengan $0 \%$ berdasarkan standarisasi TIPHON maka Packet Loss termasuk dalam kategori sangat bagus.

\section{KESIMPULAN}

Berdasarkan hasil penelitian, perancangan dan implementasi perancangan sistem peminjaman alat dan peralatan menggunakan RFID studi kasus di laboratorium teknik elektro IT Telkom Purwokerto, dapat disimpulkan sebagai berikut: Sensor RFID reader (MRFC522) dapat bekerja sesuai dengan spesifikasi datasheet, yaitu dapat membaca kartu dengan jarak kurang dari $5 \mathrm{~cm}$ dan efektif pembacaan pada jarak $1 \mathrm{~cm}$ - $3 \mathrm{~cm}$; Pembacaan sensor RFID reader dapat berjalan secara offline, namun akses menuju server membutuhkan koneksi internet dalam menjalankannya; Media browser yang dapat digunakan untuk menjalankan aplikasi website peminjaman diantaranya adalah Mozila Firefox, Google Chrome pada PC; Parameter Delay yang didapatkan dari pengambilan data secara variasi yaitu selama 1 menit, 3 menit, 5 menit, 7 menit, 10 menit, 13 menit dan 15 menit adalah berkisar 2,32 detik - 2,54 detik; Throughput yang dihasilkan dari hasil pengujian didapatkan 937,23 bps - 1029,43 bps berdasarkan standarisasi TIPHON maka Throughput yang dihasilkan dikategorikan sangat bagus; Presentase Packet Loss yang dihasilkan adalah $-0,01 \%-0 \%$ berdasarakan standarisari TIPHON termasuk dalam kategori sangat bagus. 


\section{REFERENSI}

[1] D. Yusuf, "SISTEM PEMINJAMAN BARANG DI PERUSAHAAN MENGGUNAKAN TEKNOLOGI RFID Dani," $J$. Technol., vol. 6, no. 14, pp. 49-58, 2017.

[2] A. Ruslan, "Sistem Peminjaman Dan Keamanan Pada Perpustakaan Menggunakan RFID," UNIVERSITAS ISLAM NEGERI ALAUDDIN MAKASSAR, 2018.

[3] B. B. Firdaus, "Rancang Bangun Alat Penampil Judul Buku Pada Perpustakaan Menggunakan RFID Berbasis Arduino," Sekolah Tinggi Teknologi Telematika Telkom, 2017.

[4] M. R. Adhitama, "Analisis Pembacaan dan Penulisan Data Buku Menggunakan RFID Mifare RC-522 untuk Perpustakaan,” J. Sist. dan Inform., vol. 14, no. 1, pp. 23-34, 2019, doi: 10.30864/jsi.v14i1.228.

[5] C. P. Buana, "RANCANG BANGUN SISTEM DETEKSI DINI KEBAKARAN HOTEL SECARA REAL TIME BERBASIS INTERNET OF THINGS,” 2020. 